\title{
Clinical genetics: Compassion, access, science, and advocacy
}

\author{
Edward R.B. McCabe, MD, PhD
}

You have given me a great honor by electing me President of the American College of Medical Genetics. I want to thank you most sincerely for this honor.

In my presidential address, I will describe several issues in clinical genetics that require not only exacting science but also a blend of compassion and advocacy that we, as clinical geneticists, bring to these issues. I will include the theme enunciated by Dr. Rodney Howell when he was President of ACMG (1999-2000), that the ACMG will work to "ensure that the public directly benefits from the vast amount of information being derived from genomic research." In this way, our college can help fulfill the need for everyone to have full and equal access to genetic information and genetic health professionals. We are all advocates for our patients individually. We must also be advocates for our patients collectively, and advocates for our discipline, so that we can assist our field in moving forward effectively to impact positively on the health care for our entire population.

Before I begin my case-based presentation of four clinical vignettes describing selected issues for us to consider in clinical genetics, I want to give you my larger view of the revolution in thinking that genomic sequencing is bringing to all of us. Copernicus moved us to the modern heliocentric reality of our solar system and away from the human-focused concept of our planetary system with earth at the center, an egocentric view that had been espoused by prominent thinkers such as Aristotle and Ptolemy. Genetics and genomics are moving us away from an analogous human-focused, egocentric view of life on earth. We have learned that the laws of Mendel hold broadly among living organisms, DNA is the chemical basis of heredity for all free-living organisms, and the sequence and the organization of the human genome are remarkably similar with other organisms. For example, the genomic organization and expression pattern of the homeobox genes demonstrate striking resemblances between Drosophila and human. ${ }^{2}$ Genomic analyses indicate that, among humans, our sequences vary by, at most, approximately 1 nucleotide in $1,000 .^{3}$ This knowledge brings us to a better appreciation of how closely each one of us

\footnotetext{
The ACMG presidential address was presented March 1, 2001.

President, American College of Medical Genetics; Professor and Executive Chair, Department of Pediatrics, UCLA School of Medicine; and Physician-in-Chief, Mattel Children's Hospital at UCLA.

Edward R.B. McCabe, MD, PhD, Department of Pediatrics, UCLA School of Medicine, 10833 Le Conte Avenue, Los Angeles, CA 90095-1752.
}

is related to all other humans and to all life. With this recognition should come a greater compassion among all humans, advocacy for all organisms, and a profound sense of responsibility for life on this planet.

Scientific and technological advances are fundamentally changing the practice of clinical genetics. As clinicians, we are also humanists, students of human nature and human affairs. ${ }^{4}$ Here, we will consider real and impending issues in clinical genetics, and the roles of compassion, access, and advocacy in addressing these issues.

\section{National agenda for newborn screening}

A couple with two children and another on the way recently moved from Massachusetts. They interview a pediatrician in their new state and inquire about the delivery and postpartum care. The couple notes that they were extremely pleased with the expansion of the Massachusetts newborn screening program between their first and second children, with the addition of the new tandem mass spectrometry (MS/MS) technology adding 20 or more diseases to the panel. They are extremely concerned when they learn that their new state has not added this technology.

Public health programs within the USA are organized by each state, and newborn screening exists within this statebased public health system. In order to address differences in newborn screening programs between states, as well as other issues, the Newborn Screening Task Force was cosponsored by the American Academy of Pediatrics (AAP) and the Maternal and Child Health Bureau (MCHB), a unit within the Health Resources and Services Administration (HRSA), Department of Health and Human Services (DHHS). The report of the Task Force was published as a supplement to the journal of the AAP, Pediatrics, in August 2000.5

The Task Force report ${ }^{5}$ emphasized that newborn screening is a system that spans activities ranging from pretest education through sample acquisition and testing, to result reporting, confirmation of abnormal results, and clinical follow-up and management. The Task Force also called for a national agenda to address the striking disparities from state-to-state in the diseases included in the screening menu and in the technologies used in the screening programs. Some states screen for as few as three diseases and others for more than 30 disorders. Testing methods also vary considerably, with some state programs using methodologies described in the 1960s and others employing state-of-the-art technologies. 
The March of Dimes Birth Defects Foundation (MOD) responded to the Task Force report by expressing concern that the Task Force had not gone far enough and should have specified the diseases to be included in the national agenda. ${ }^{6}$ The MOD also criticized the emphasis in the Task Force report on cost-effectiveness in the assessment of newborn screening.

Communication between the MOD, MCHB, AAP, and ACMG has led to a plan for developing a national agenda. (Subsequent to this presentation, at the 2001 ACMG meeting, Dr. Michelle Puryear, chief of the Genetics Disease Branch, $\mathrm{MCHB}$, announced that ACMG would be the contractor for a 2 -year process to develop this national agenda.) This process will recommend the core diseases and technologies that should be applied in the screening of every baby born in the U.S.A. and will be an important step in eliminating disparities in screening between the states. The challenge of implementation in each state will require considerable effort and political will.

\section{Gene patents and sample ownership}

A family with three children, two of whom have a rare autosomal recessive disease, find a geneticist who is doing research on this disorder. They are passionate in their desire to participate in the research identifying the disease gene with a goal of developing better therapy. The family rejects the university-approved consent form, and presents the investigator with model consent language from a foundation focused on this disease. The consent states that the foundation will share in any intellectual property income with the university.

The patenting of the human genome has captured the public's interest. A British waitress is said to have walked into the British patent office and requested the appropriate forms so that she could patent her own genome before someone else did this. Even if apocryphal, this story captures the often heard sentiment that we will one day wake up and find that someone else owns our genome.

During the week of February 12, 2001, achievement of a draft sequence of the human genome was celebrated. ${ }^{7,8}$ The public genome project, an international effort that officially began October 1, 1990, published its sequence daily on the internet. ${ }^{7}$ Celera, a private organization, began its human genome sequencing efforts on September 8, 1999, and used the publicly available data as well as sequence generated by their random shotgun strategy. ${ }^{8}$

Until recently, the U.S. Patent and Trade Office (PTO) considered and awarded applications for gene patents founded on homology-based presumptions of use. The American College of Medical Genetics, under the leadership of Drs. Rod Howell and Michael Watson, took a highly visible position on gene patenting and licensure that has been extremely influential in the subsequent debate. ${ }^{9}$ Recently, the PTO raised the stringency of requirements for proof of utility in applications. ${ }^{10}$

The ACMG participated in a group of presentations on patenting of genes and their licensure for clinical analysis made to the DHHS Secretary's Advisory Committee on Genetic Testing (SACGT). ${ }^{11}$ As a result of these presentations and subsequent discussion, the SACGT sent a letter to former DHHS Secretary
Shalala, recommending careful consideration of the issues involved in gene patenting.

As illustrated by the clinical vignette at the beginning of this section, issues also arise about ownership of individual patients' samples. Case law and university policies, particularly in California, have been influenced by the lawsuit Moore v. Regents of the University of California. ${ }^{12}$ Mr. Moore provided a sample to investigators who developed a cell line from the sample that proved to be valuable commercially. He sued for a share of the profits. The California Supreme Court determined that Mr. Moore had no ownership rights to the cell line.

Another case concerned with ownership and access to technological advances involves Canavan disease. ${ }^{13}$ A group of parents of children with this disorder argued that they provided samples and funding to an investigator who was then at Miami Children's Hospital. Following successful cloning and characterization of the gene, the institution sought restrictive licensure and what was perceived as a high licensing fee. Difficulties attributed to problems in identifying a licensee resulted in what the families considered a lack of access to Canavan disease testing. A suit has been filed naming Miami Children's Hospital as a defendant. ${ }^{13}$

The Pseudoxanthoma Elasticum (PXE) Foundation, a patient advocacy group founded by parents of children with this autosomal recessive disease, has taken a different approach to the issue of ownership. ${ }^{13,14}$ When the PXE Foundation established a relationship with researchers to identify the gene responsible for PXE, they developed a formal agreement describing a partnership in the enterprise, with the Foundation sharing in any intellectual property that might derive from the research that they supported. The Foundation maintained that they were interested not so much in any money that might result from this intellectual property but they wanted to maintain control of any intellectual property that might derive from the research.

Ownership of individuals' samples and the genetic information from these samples is an area that continues to evolve. Such samples are valuable commodities: one state reportedly sold newborn screening samples to a private company to be used in genetic test development. The interface of intellectual property and genetics is an area in which the ACMG has been visible in the past and in which we will continue to be active.

\section{Genetic discrimination}

A patient who works for a small self-insured company has a positive family history for emphysema on both her mother's and her father's sides. Her physician recommends that she have a number of tests performed, including one for $\alpha 1$-antitrypsin $(\alpha 1 A T)$ deficiency. When the $\alpha 1 A T$ test is reported to be abnormal, the physician tells her that this may explain the emphysema in her family and places her at very high risk for this lung disease. Her physician reports the results of the evaluation to her insurance company as required. Several days later she is called into the office of her employer and fired.

This vignette is adapted from an actual case brought by Equal Employment Opportunity Commission (EEOC) under 
the Americans with Disabilities Act (ADA). ${ }^{15}$ In the actual case, the individual demonstrated some compromise of pulmonary function at the time she had the genetic testing. The court found in favor of the plaintiff.

Genetic discrimination has been a major focus of media attention. President Clinton signed an Executive Order in February 2000, which broadly prohibited genetic discrimination among applicants for federal positions and among federal employees. ${ }^{16}$ The SACGT was charged by the U.S. Surgeon General and former DHHS Assistant Secretary of Health, Dr. David Satcher, to reach out to the American public to determine their feelings about genetic testing. ${ }^{17}$ The results of this public outreach effort indicated serious concerns regarding genetic discrimination and included reported incidences of genetic information adversely affecting employment and insurability. As a result of the public outreach and its deliberations, the SACGT sent a letter to former DHHS Secretary Shalala, recommending support of legislation to prohibit genetic discrimination. ${ }^{18}$ Federal legislative efforts to prevent genetic discrimination are ongoing.

\section{Oversight of genetic testing}

A woman with a positive family history of breast and ovarian cancer was tested for BRCA1 mutations in a private laboratory. The test result was reported positive for a BRCA1 mutation. After receiving counseling regarding her risks and options, she elected to have a prophylactic oophorectomy. While she was contemplating a prophylactic mastectomy, she was notified that her results were reported incorrectly, and she had no evidence of a BRCA1 mutation. The private laboratory that had reported the erroneous result had gone out of business.

The vignette described here is based on an actual case. ${ }^{19}$ Some have said that policy should not be implemented based on single cases. But, we are all aware of the power that such incidents may have, and we know that policy may be instituted hastily in reaction to individual events. Many of us feel that it is better to develop policy in a proactive rather than a reactive manner.

Parameters used to evaluate clinical chemistry tests include analytical validity, clinical validity, and clinical utility. ${ }^{20}$ Analytical validity represents the technical accuracy of the test and its ability to measure the intended analyte. Clinical validity indicates the ability of the test to perform in the clinical setting. Clinical utility considers the ability of the test results to be used meaningfully in clinical decision-making for individual patients.

The SACGT was charged with determining whether oversight of genetic testing was adequate. ${ }^{21}$ After public outreach, the SACGT determined that oversight was inadequate and recommended increased oversight for genetic testing. ${ }^{22}$ The Food and Drug Administration (FDA) was recommended as the lead agency in this oversight, since the FDA already had statutory and regulatory authority over such testing. SACGT indicated that the FDA should develop an innovative approach that would not become a bottleneck in the implementation of genetic technologies for clinical testing. SACGT also recom- mended that FDA engage experts and professional groups outside of the agency to assist in the implementation and performance of oversight and that different processes be utilized for existing tests, for which data are readily available to evaluate performance, and new tests for which data may be more limited. Members of the ACMG, including Drs. Howell and Watson, have been active in responding to SACGT and working with FDA to develop oversight processes.

Early efforts by SACGT to develop processes for initial evaluation of new tests by the FDA focused on flow diagrams with key decision points, such as a test's analytical validity, whether it would be used for population screening, and whether the disease tested is common or rare. ${ }^{23}$ The feedback received from individual professionals and professional organizations, including ACMG, indicated flaws in this simplistic approach. ${ }^{24,25}$

At the SACGT meeting held February 15 to 16, 2001, FDA reported that a workgroup of the Association for Molecular Pathology (AMP), in concert with FDA staff, developed the concept of a template-driven process. ${ }^{24}$ The template represented a matrix of specific elements, such as intended use. One goal of the review template would be to begin to generate the elements for labeling. This labeling would become the "package insert" for the genetic test that would inform health professionals and the public regarding what the test is capable of doing and what limitations there may be on its capabilities.

\section{Summary}

We live in an amazing era for genetics. The recent reports of the draft human genomic sequence ${ }^{7,8}$ represent only the beginning in our understanding of the human genome. As medical geneticists, we will see a dramatic increase in the clinical applications of genetic information.

We have an obligation, not only to harness this technology for the benefit of our patients, but also to ensure that all have access to this technology and that it is used for everyone's benefit in the most compassionate way. We must be advocates for our patients individually and collectively.

Thank you again very much for electing me to a leadership role in the ACMG, an active, dynamic, and highly effective organization. I am extremely proud to serve you.

\section{References}

1. Howell RR. Some major milestones and future directions. Genet Med 2000;2:255258.

2. Mark M, Rijili FM, Chambon P. Homeobox genes in embryogenesis and pathogenesis. Pediatr Res 1997;42:421-429.

3. The International SNP Map Working Group. A map of human genome sequence variation containing 1.42 million single nucleotide polymorphisms. Nature 2001; 409:928-932.

4. Webster's New World Dictionary. Third College ed. Cleveland, OH: Simon \& Schuster, Inc., 1988.

5. Newborn Screening Task Force. Serving the family from birth to the medical home. Newborn screening: a blueprint for the future - a call for a national agenda on state newborn screening programs. Pediatrics 2000;106S:386-427. (http://www.pediatrics.org/cgi/content/full/106/2/S1/389)

6. Howse JL, Katz M. The importance of newborn screening. Pediatrics 2000;106:595.

7. International Human Genome Sequencing Consortium. Initial sequencing and analysis of the human genome. Nature 2001;409:860-921. 


\section{ACMG presidential address}

8. Venter JC, Adams MD, Myers EW, Li PW, Mural RJ, Sutton GG et al. The sequence of the human genome. Science 2001;291:1304-1351.

9. American College of Medical Genetics position statement on gene patents and accessibility of gene testing. Genet Med 1999;1:237.

10. U.S. issues stiffer regulations on frivolous patenting of genes. New York Times 1/6/ 2001; Business/Financial Desk section.

11. Secretary's Advisory Committee on Genetic Testing, 2000 (http://www4.od.nih.gov/ oba/sacgt/transcripts/sacgttrans6-7-00.htm).

12. California Supreme Court. Moore v. the Regents of the University of California, 51 CAL.3D 120, 1990

13. Marshall E. Families sue hospital, scientist for control of Canavan gene. Science 2000;290:1062.

14. Smaglik P. Tissue donors use their influence in deal over gene patent terms. Nature 2000;407:821.

15. Alpha 1 Association, Programs, Newsmakers, Terri Seargent, 2001 (http:// www.alpha1.org/programs/newsmakers_seargent.htm).

16. Executive Order 13145: To Prohibit Discrimination in Federal Employment Based on Genetic Information. Federal Register 2000;65:6877-6880.
17. Secretary's Advisory Committee on Genetic Testing, 2000 (http://www4.od.nih.gov/ oba/sacgt/sacgtcharter.htm).

18. Secretary's Advisory Committee on Genetic Testing, 2000 (http://www4.od.nih.gov/ oba/sacgt/toshalala.pdf).

19. Underwood A. When. "knowledge" does damage. Newsweek 4/10/2000;135.

20. Secretary's Advisory Committee on Genetic Testing: Notice of meeting and request for public comments on oversight of genetic testing. Federal Register 1999;64:6727367289.

21. Secretary's Advisory Committee on Genetic Testing: Notice of meeting. Federal Register 2000;65:21094-21109.

22. Secretary's Advisory Committee on Genetic Testing, 2000 (http://www4.od.nih.gov/ oba/sacgt/reports/sacgtfinal.pdf).

23. Secretary's Advisory Committee on Genetic Testing. Federal Register 2000;65:76643-76646

24. Secretary's Advisory Committee on Genetic Testing, 2001 (http://www4.od.nih.gov/ oba/sacgt/transcripts/Feb15gttrans.pdf).

25. Secretary's Advisory Committee on Genetic Testing, 2001 (http://www4.od.nih.gov/ oba/sacgt/transcripts/Feb16gttrans.pdf). 